\title{
Interleukin-32 promotes lipid accumulation through inhibition of cholesterol efflux
}

\author{
ZONGLEI XU ${ }^{1}$, AIZHI DONG ${ }^{2}$, ZERUI FENG $^{3}$ and $\mathrm{JING} \mathrm{LI}^{4}$ \\ ${ }^{1}$ Department of Internal Medicine Cardiovascular Medicine, Liaocheng Development Hospital, \\ Liaocheng, Shandong 252000; ${ }^{2}$ VIP Ward, Shandong Liaocheng No. 2 People's Hospital; \\ ${ }^{3}$ Department of Internal Medicine Cardiovascular Medicine, Shandong Liaocheng No. 2 People's Hospital, \\ Liaocheng, Shandong 252600; ${ }^{4}$ Department of Internal Medicine Cardiovascular Medicine, \\ Ankang City Central Hospital, Ankang, Shanxi 725000, P.R. China
}

Received February 9, 2016; Accepted February 14, 2017

DOI: $10.3892 /$ etm.2017.4596

\begin{abstract}
Interleukin-32 (IL-32) is a pro-inflammatory cytokine and its effects in various inflammatory diseases have been investigated. However, the role of IL-32 on atherosclerosis, an inflammatory disease, remains unknown. The present study examined the use of IL-32 $\alpha$, the most abundant transcript of IL-32, in the treatment of oxidized low-density lipoprotein (ox-LDL)-stimulated THP-1 macrophages for $24 \mathrm{~h}$, which simulates a foam cell formation model. The effect of IL-32 $\alpha$ (20, 50 and $100 \mathrm{ng} / \mathrm{ml})$ on lipid deposition in the macrophages was analyzed using Oil Red O staining, while the cholesterol efflux on apolipoprotein A-I was also measured. The mRNA and protein expression levels of peroxisome proliferator-activated receptor $\gamma$ (PPAR $\gamma)$, liver X receptor $\alpha$ (LXR $\alpha$ ), ATP-binding cassette transporter A1 (ABCA1) and ABCG1 were quantified by reverse transcription-quantitative polymerase chain reaction and western blot analysis, respectively. The results indicated that IL-32 $\alpha$ exposure enhanced the lipid deposition and attenuated the cholesterol efflux from ox-LDL-stimulated THP-1 macrophages in a dose-dependent manner. Furthermore, the expression levels of ABCA1, LXR $\alpha$ and PPAR $\gamma$ were dose-dependently decreased by IL-32 $\alpha$ at the mRNA and protein levels. Addition of the PPAR $\gamma$ agonist 15d-PGJ2 or overexpression of PPAR $\gamma$ in THP-1 macrophages abrogated the IL-32 $\alpha$-mediated inhibition of cholesterol efflux and reversed the IL-32 $\alpha$-mediated downregulation of ABCA1 and LXR $\alpha$. In conclusion, IL-32 $\alpha$ enhances lipid accumulation and inhibits cholesterol efflux from ox-LDL-exposed
\end{abstract}

Correspondence to: Dr Jing Li, Department of Internal Medicine Cardiovascular Medicine, Ankang City Central Hospital, 85 Jinzhou South Road, Ankang, Shanxi 725000, P.R. China

E-mail: lijing20060912@qq.com

Key words: interleukin-32, peroxisome proliferators-activated receptor $\gamma$, liver X receptor $\alpha$, ATP-binding cassette transporter A1, cholesterol efflux
THP-1 macrophages by regulating the PPAR $\gamma$-LXR $\alpha$-ABCA1 pathway.

\section{Introduction}

Atherosclerosis is a chronic metabolic disorder, which is characterized by the formation and accumulation of lipid plaques in the arteries and by inflammatory responses (1-4). The main lipid-laden cells are known as foam cells and are a key attribute of atherosclerotic lesions (2-4). In atherosclerotic lesions, macrophages that express scavenger receptors on their plasma membranes uptake low-density lipoprotein (LDL) deposited into blood vessel walls, and are converted into foam cells. Foam cells can secrete various inflammatory cytokines and promote the development of atherosclerosis (5). Therefore, preventing foam cell formation by decreasing cholesterol influx and increasing cholesterol efflux may be a potential treatment strategy for atherogenesis.

Macrophage-specific reverse cholesterol transport (RCT) is one of the most important high density lipoprotein (HDL)-mediated cardioprotective mechanisms (6). RCT is a process during which cholesterol in peripheral cells is effluxed into circulating HDL and transported back into the liver for excretion in bile and feces (7). The cholesterol efflux from cells to HDL is a rate-limiting step of RCT (8). The family of ATP-binding cassette (ABC) transporters, including ABCA1 and ABCG1, has been demonstrated to serve a critical role in the RCT pathway by promoting the translocation of cholesterol across cellular bilayer membranes $(9,10)$. ABCA1 enhances the cholesterol efflux to lipid-poor apolipoproteins, such as apolipoprotein A-I (apoAI), while ABCG1 increases the cholesterol efflux to HDL (11). The expression levels of ABCA1 and ABCG1 are regulated, to a certain extent, by the peroxisome proliferator-activated receptor $\gamma(\operatorname{PPAR} \gamma)$ and liver X receptor $\alpha(\mathrm{LXR} \alpha)(12)$.

Interleukin-32 (IL-32) was originally identified as natural killer (NK) 5 transcript 4, induced by IL-18 in NK cells (13). Due to its cytokine-like characteristics and its critical role in inflammation, it was renamed as IL-32 (13). IL-32 is promoted by interferon- $\gamma$, IL-18 and IL-12 in various cell types, such 
as epithelial cells. In addition, it induces the production of various pro-inflammatory cytokines, including tumor necrosis factor-alpha (TNF- $\alpha)$, IL-8, IL-1 $\beta$ and IL-6, as well as of numerous chemokines in monocytes and macrophages (13). There are six isoforms of IL-32 by alternative splicing, namely IL-32 $\alpha$, IL-32 $\beta$, IL32 $\gamma$, IL-32 $\delta$, IL-32 $\varepsilon$, and IL-32 $\zeta$ (13), with IL-32 $\alpha$ being the most abundant transcript (14). As IL-32 is a pro-inflammatory cytokine, its effects on various inflammatory diseases, such as rheumatoid arthritis and inflammatory bowel disease, have been explored (15). However, the role of IL-32 on cholesterol efflux remains unknown. In the present study, IL-32 $\alpha$ was used to treat oxidized LDL (ox-LDL)-stimulated THP-1 macrophages in order to investigate the effects of IL-32 $\alpha$ on cholesterol efflux.

\section{Materials and methods}

Cell culture. The human monocyte THP-1 cell line was purchased from the American Type Culture Collection (Manassas, VA, USA). THP-1 cells were cultured in RPMI 1640 medium supplemented with $10 \%(\mathrm{v} / \mathrm{v})$ fetal calf serum, $0.1 \%$ nonessential amino acids, $100 \mathrm{U} / \mathrm{ml}$ penicillin and $100 \mathrm{mg} / \mathrm{ml}$ streptomycin. Cells were incubated at $37^{\circ} \mathrm{C}$ in a humidified atmosphere of $5 \% \mathrm{CO}_{2}$. THP-1 cells were treated with $160 \mathrm{nmol} / \mathrm{l}$ phorbol 12-myristate 13-acetate (PMA) for $72 \mathrm{~h}$ and fully differentiated into macrophages. The differentiated THP-1 macrophages were then washed extensively with phosphate-buffered saline (PBS), and cells were incubated in serum-free medium containing $0.1 \%$ bovine serum albumin (BSA) and $50 \mu \mathrm{g} / \mathrm{ml}$ human ox-LDL (Anhui Yiyuan Biotechnology Co., Ltd., Anhui, China) for a further 48 h. All reagents for cell culture were obtained from Invitrogen (Thermo Fisher Scientific, Inc., Waltham, MA, USA). PMA was purchased from Sigma-Aldrich (Merck KGaA, Darmstadt, Germany). Recombinant human IL-32 $\alpha$ was obtained from R\&D Systems (Minneapolis, MN, USA).

Morphological examination. THP-1 macrophages were incubated in chamber slides in serum-free medium (containing $0.1 \%$ BSA) with or without IL-32 $\alpha(20,50$, and $100 \mathrm{ng} / \mathrm{ml})$ for $6 \mathrm{~h}$, and then exposed to $50 \mu \mathrm{g} / \mathrm{ml}$ ox-LDL for $24 \mathrm{~h}$. Cells were washed with PBS for three times, fixed with $5 \%$ formalin solution in PBS for $30 \mathrm{~min}$, and stained with Oil Red $\mathrm{O}$ for a further $30 \mathrm{~min}$. Subsequently, cells were counterstained with hematoxylin for $5 \mathrm{~min}$. Finally, images of the stained cells were captured using a Leica optical microscope (Leica Microsystems GmbH, Wetzlar, Germany). The number of stained cells was counted in five random fields (magnification, x100) for each group.

Plasmid construction. The pcDNA3.1-PPAR- $\gamma$ plasmid was constructed by inserting the human PPAR- $\gamma$ cDNA (Genbank no., NM_138711.3) into a pcDNA3.1 mammalian expression vector. The full-length cDNA sequence was amplified using Takara Ex Taq DNA polymerase (Takara Bio, Inc., Otsu, Japan), according to the manufacturer's protocol. The primers used were as follows: PPAR- $\gamma$ forward, 5'-GGGGGTACCATGACCATGGTTG-3' and reverse, 5'-GGGCTCGAGCTAGTACAAGTCC-3'. Thermocycling conditions were as follows: Initial denaturation at $95^{\circ} \mathrm{C}$ for
$5 \mathrm{~min}$, followed by 35 cycles of $95^{\circ} \mathrm{C}$ for $30 \mathrm{sec}, 59^{\circ} \mathrm{C}$ for $30 \mathrm{sec}$, and $72^{\circ} \mathrm{C}$ for $45 \mathrm{sec}$. All constructs were sequenced to ensure accuracy.

Cell transfection. THP-1 macrophages (2x106 cells/well) were seeded in 6-well plates and incubated overnight prior to transfection. pcDNA3.1-PPAR- $\gamma$ or pcDNA3.1 vector was added to each well at a final concentration of $50 \mathrm{nM}$ and was incubated with Lipofectamine 2000 (Invitrogen; Thermo Fisher Scientific, Inc.) at room temperature for $30 \mathrm{~min}$. The pcDNA3.1-transfected group served as a negative control.

Cholesterol efflux. THP-1 macrophages were assigned to the following groups: Untreated control, ox-LDL, ox-LDL+IL-32 $\alpha$, ox-LDL+15d-PGJ2, ox-LDL+DMSO, ox-LDL+IL-32 $\alpha+15 d-P G J 2$, and ox-LDL+IL-32 $\alpha+$ DMSO. THP-1 macrophages were cultured until they reached $60 \%$ confluence, and were then labeled with $0.2 \mu \mathrm{Ci} / \mathrm{ml}\left[{ }^{3} \mathrm{H}\right]$ cholesterol (PerkinElmer, Inc., Waltham, MA, USA) for $24 \mathrm{~h}$. Fresh serum-free medium with $0.1 \%$ BSA containing the PPAR $\gamma$ agonist $15 \mathrm{~d}-\mathrm{PGJ} 2(5 \mu \mathrm{M}$; Merck \& Co., Inc., Whitehouse Station, NJ, USA) or $0.1 \%$ dimethyl sulfoxide (DMSO; Sigma-Aldrich; Merck KGaA) was added to THP-1 macrophages for $1 \mathrm{~h}$, followed by exposure to IL-32 $\alpha(50 \mathrm{ng} / \mathrm{ml})$ for a further $6 \mathrm{~h}$. Ox-LDL was then added to cells and incubated for another $24 \mathrm{~h}$. Equilibrated $\left[{ }^{3} \mathrm{H}\right]$ cholesterol-labeled cells were washed with PBS and incubated in efflux medium [RPMI 1640 medium and 0.1\% BSA with $25 \mu \mathrm{g} / \mathrm{ml}$ human apoA-I (Sigma-Aldrich; Merck KGaA)] for $4 \mathrm{~h}$. Cells were centrifuged at $14,000 \times \mathrm{g}$ for $15 \mathrm{~min}$, and the supernatants were then collected. Single layer cells were dissolved in isopropanol. Medium and cell-associated $\left[{ }^{3} \mathrm{H}\right]$ cholesterol was examined by liquid scintillation counting. The percentage of apoA-I-mediated cholesterol efflux was calculated as follows: Cholesterol efflux $(\%)=($ total media counts $) /($ total cellular counts + total media counts) $\times 100 \%$.

Reverse transcription-quantitative polymerase chain reaction $(R T-q P C R)$. Total RNA was extracted using TRIzol reagent (Invitrogen; Thermo Fisher Scientific, Inc.), and $2 \mu \mathrm{g}$ total RNA was used as the template for reverse transcription using a PrimeScript RT reagent kit (Takara Bio, Inc., Otsu, Japan) cDNA was used as template for qPCR on the Light Cycler system (Roche Diagnostics, Shanghai China) using SYBR-Green I Master mixture (Roche Diagnostics). Cycling conditions were as follows: Initial denaturation at $95^{\circ} \mathrm{C}$ for $5 \mathrm{~min}$, then 35 cycles of denaturation at $95^{\circ} \mathrm{C}$ for $20 \mathrm{sec}$, annealing at $58^{\circ} \mathrm{C}$ for $30 \mathrm{sec}$ and extension at $72^{\circ} \mathrm{C}$ for $50 \mathrm{sec}$. The primers used for $\mathrm{qPCR}$ in the present study were synthesized by Sangon Biotech (Shanghai, China) and are listed in Table I. $\beta$-actin was used as the housekeeping gene control for qPCR. The threshold cycle $(\mathrm{Cq})$ values were used to calculate the fold change in transcript levels using the $2^{-\Delta \Delta \mathrm{Cq}}$ method (16), as follows: Fold change $=2-[($ Cq target- $-\mathrm{Cq} \beta$-actin $)$ of siRNA $]-[(\mathrm{Cq}$ target-Cq $\beta$-actin $)$ of control].

Western blot assay. Ox-LDL-stimulated THP-1 macrophages were washed with PBS for three times and lysed in lysis buffer (20 mM HEPES, $300 \mathrm{mM} \mathrm{NaCl}, 0.2 \mathrm{mM}$ EDTA, $1.5 \mathrm{mM} \mathrm{MgCl}_{2}$ and $1 \%$ Triton X-100) containing 
Table I. Primers for quantitative polymerase chain reaction analysis.

\begin{tabular}{ll}
\hline Gene & \multicolumn{1}{c}{ Sequence } \\
\hline ABCA1 & Forward: 5'-AACAGTTTGTGGCCCTTTTG-3' \\
& Reverse: 5'-AGTTCCAGGCTGGGGTACTT-3' \\
ABCG1 & Forward: 5'-GGTTCTTCGTCAGCTTCGAC-3' \\
& Reverse: 5'-GTTTCCTGGCATTCAGGTGT-3' \\
PPAR $\gamma$ & Forward:5'-GGCAATTGAATGTCGTGTCTGTGGAGATAA-3' \\
LXR $\alpha$ & Reverse:5'-AGCTCCAGGGCTTGTAGCAGGTTGTCTTGA-3' \\
$\beta$-actin & Forward: 5'-GCGAGGGCTGCAAGGGATTCT-3' \\
& Reverse: 5'-ATGGGCCAAGGCGTGACTCG-3' \\
& Forward: 5'-TCATGAAGTGTGACGTTGACATCCGT-3' \\
& Reverse: 5'-CTTAGAAGCATTTGCGGTGCACGATG-3' \\
\hline
\end{tabular}

ABC, ATP-binding cassette transporter; LXR $\alpha$, liver X receptor $\alpha$; PPAR $\gamma$, peroxisome proliferator-activated receptor $\gamma$.

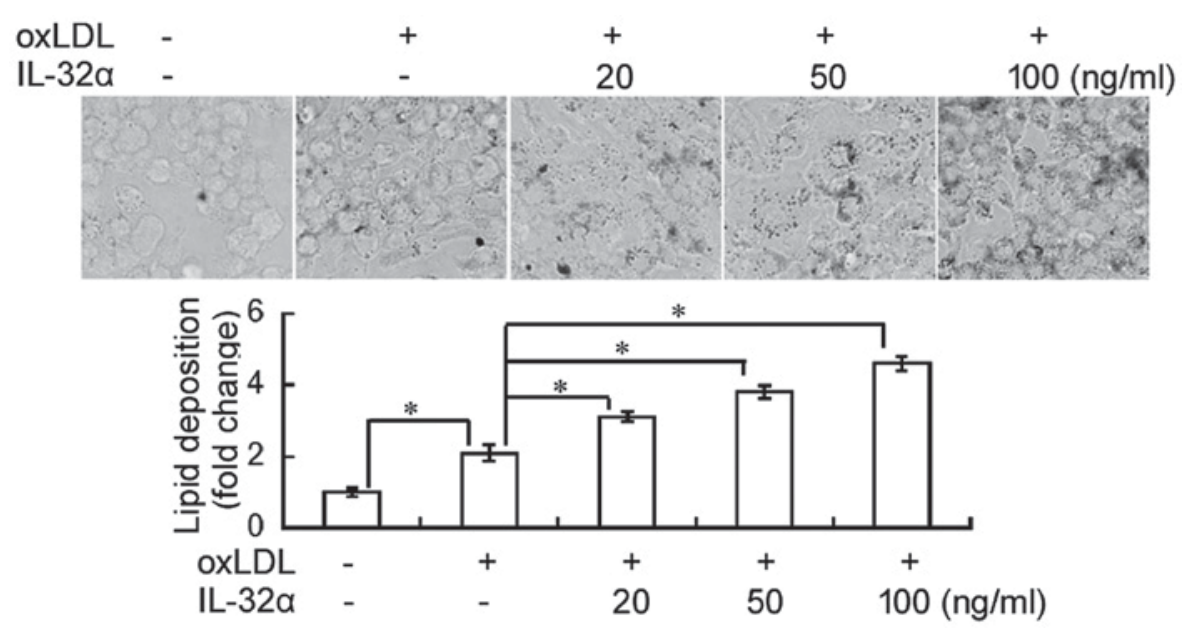

Figure 1. Effects of IL-32 $\alpha$ on lipid accumulation in ox-LDL-stimulated THP-1 macrophages. THP-1 macrophages were pretreated with different concentrations of IL-32 $\alpha(20,50,100 \mathrm{ng} / \mathrm{ml})$ for $6 \mathrm{~h}$, followed by incubation with ox-LDL for $72 \mathrm{~h}$. Subsequently, cells were stained with Oil Red O staining. Data are expressed as the mean \pm standard deviation $(n=3)$. $P<0.05$. IL-32 $\alpha$, interleukin-32 $\alpha$; ox-LDL, oxidized low-density lipoprotein.

$2 \%$ phenylmethylsulfonyl fluoride. Total protein concentrations were measured with a Pierce BCA Protein Assay kit (Thermo Fisher Scientific, Inc.). Subsequently, $20 \mu \mathrm{g}$ cell lysates were subjected to $10 \%$ SDS-polyacrylamide gel electrophoresis, and proteins were transferred to nitrocellulose membranes (EMD Millipore, Billerica, MA, USA). Membranes were blocked with $5 \%$ non-fat milk for $1 \mathrm{~h}$ at room temperature and probed with antibodies against ABCA1 (sc-81779; 1:500 dilution), ABCG1 (sc-20795; 1:500 dilution), PPAR $\gamma$ (sc-6285; 1:500 dilution), LXR $\alpha$ (sc-1202; 1:500 dilution) and anti-human $\beta$-actin (sc-47778; 1:1,000 dilution; all from Santa Cruz Biotechnology, Inc., Santa Cruz, CA, USA) in antibody dilution buffer [5\% non-fat milk in $1 \mathrm{X}$ Tris-buffered saline/0.1\% Tween-20 (TBST)] at $4^{\circ} \mathrm{C}$ overnight. Next, the membranes were washed with TBST for three times and then incubated with horseradish peroxidase-conjugated goat anti-rabbit IgG (sc-2004; 1:2,000 dilution) or goat anti-mouse IgG (sc-2005; 1:1,000 dilution; Santa Cruz Biotechnology, Inc.) at room temperature for $1 \mathrm{~h}$. After washing with TBST, the membranes were subjected to an enhanced chemiluminescence advanced system (GE
Healthcare Life Sciences, Chicago, IL, USA). $\beta$-actin was used as a loading control. The protein bands were analyzed using Quantity One software (version 4.6.2; Bio-Rad Laboratories Inc., Hercules, CA, USA).

Statistical analysis. SPSS software version 13.0 (SPSS, Inc., Chicago, IL, USA) was used to perform statistical analysis. Data are presented as the means \pm standard deviation of three experiments, or are representative of experiments repeated at least three times. Comparisons were conducted with a one-way analysis of variance and post-hoc Tukey's tests. $\mathrm{P}<0.05$ was considered to indicate a statistically significant difference.

\section{Results}

IL-32 $\alpha$ induces lipid deposition in THP-1 macrophages. The effect of IL-32 $\alpha$ on lipid deposition in THP-1 macrophages was evaluated using Oil Red $\mathrm{O}$ staining. As shown in Fig. 1, ox-LDL exposure significantly induced lipid accumulation in THP-1 macrophages, compared with the untreated control $(\mathrm{P}<0.05)$. Notably, addition of recombinant IL-32 $\alpha$ protein 


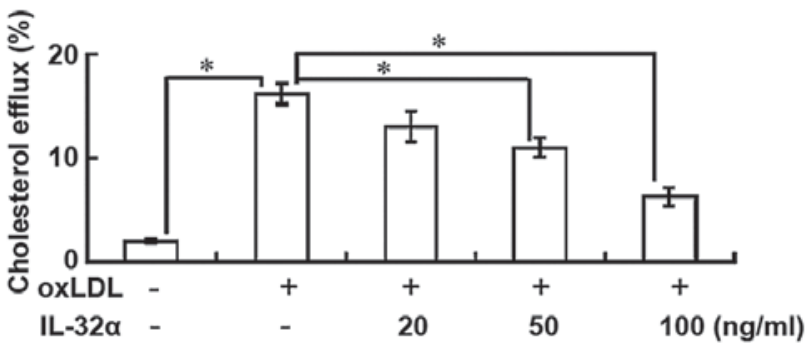

Figure 2. IL-32 $\alpha$ reduces cholesterol efflux in ox-LDL-stimulated THP-1 macophages. THP-1 macrophages were labeled with $0.2 \mu \mathrm{Ci} / \mathrm{ml}[3 \mathrm{H}]$ cholesterol for $24 \mathrm{~h}$, followed by incubation in the presence or absence of IL-32 $\alpha$ $(20,50,100 \mathrm{ng} / \mathrm{ml})$ for $6 \mathrm{~h}$, and then ox-LDL addition for a further $24 \mathrm{~h}$. Equilibrated $\left[{ }^{3} \mathrm{H}\right]$ cholesterol-labeled cells were then incubated in efflux medium (containing $25 \mu \mathrm{g} / \mathrm{ml}$ human apoA-I) for $4 \mathrm{~h}$. Data are represented as the percentages of total cells (mean \pm standard deviation; $n=3$ ). ${ }^{*} \mathrm{P}<0.05$. IL-32 $\alpha$, interleukin-32 $\alpha$; ox-LDL, oxidized low-density lipoprotein; apoA-I, apolipoprotein A-I.

significantly induced lipid deposition in ox-LDL-induced THP-1 macrophages in a concentration-dependent fashion.

$I L-32 \alpha$ reduces cholesterol efflux. The results indicated that the percentage of cholesterol efflux was significantly increased following ox-LDL exposure in THP-1 macrophages $(\mathrm{P}<0.05$; Fig. 2). However, IL-32 $\alpha$ treatment attenuated the apoA-I-mediated cholesterol efflux in a dose-dependent manner in ox-LDL-stimulated THP-1 macrophages, with a significant effect observed for the 50 and $100 \mathrm{ng} / \mathrm{ml}$ IL- $32 \alpha$ doses $(\mathrm{P}<0.05$; Fig. 2). This suggests that IL-32 $\alpha$ increased intracellular lipid accumulation by decreasing the apoA-I-mediated cholesterol efflux.

$I L-32 \alpha$ reduces the expression levels of ABCAI, LXR $\alpha$ and PPAR $\gamma$. The importance of ABCA1, ABCG1, LXR $\alpha$ and PPAR $\gamma$ in apoA-I-mediated cholesterol efflux has previously been established (13). Therefore, the present study next analyzed the effects of IL-32 $\alpha$ on the mRNA levels of these molecules by RT-qPCR in ox-LDL-stimulated THP-1 macrophages. The results demonstrated that ox-LDL treatment significantly raised the mRNA levels of ABCA1, LXR $\alpha$ and PPAR $\gamma$, compared with untreated controls $(\mathrm{P}<0.05$; Fig. $3 \mathrm{~A})$. The addition of $100 \mathrm{ng} / \mathrm{ml}$ IL-32 $\alpha$ significantly decreased the mRNA expression levels of ABCA1, LXR $\alpha$ and PPAR $\gamma$ by $59,52.9$ and $61.1 \%$, respectively, compared with the ox-LDL alone group $(\mathrm{P}<0.05$; Fig. $3 \mathrm{~A})$. However, the level of ABCG1 was not affected. Subsequently, the study explored whether the IL-32 $\alpha$-mediated inhibition of ABCA1, LXR $\alpha$ and PPAR $\gamma$ mRNA expression led to decreased expression of ABCA1, $\mathrm{LXR} \alpha$ and PPAR $\gamma$ protein using western blot analysis. As shown in Fig. 3B, IL-32 $\alpha$ also suppressed the expression of ABCA1, LXR $\alpha$ and PPAR $\gamma$ at the protein level.

Overexpression of PPAR $\gamma$ rescued IL-32 $\alpha$-mediated inhibition of cholesterol efflux. To evaluate the effects of PPAR $\gamma$ on IL-32 $\alpha$-mediated inhibition of cholesterol efflux, the PPAR $\gamma$ agonist 15d-PGJ2 was used to treat cells (Fig. 4A and B) or pcDNA3.1-PPAR $\gamma$ (Fig. 4C and D) was transfected to THP-1 macrophages. The 15d-PGJ2 treatment or overexpression of PPAR $\gamma$ significantly enhanced cholesterol efflux

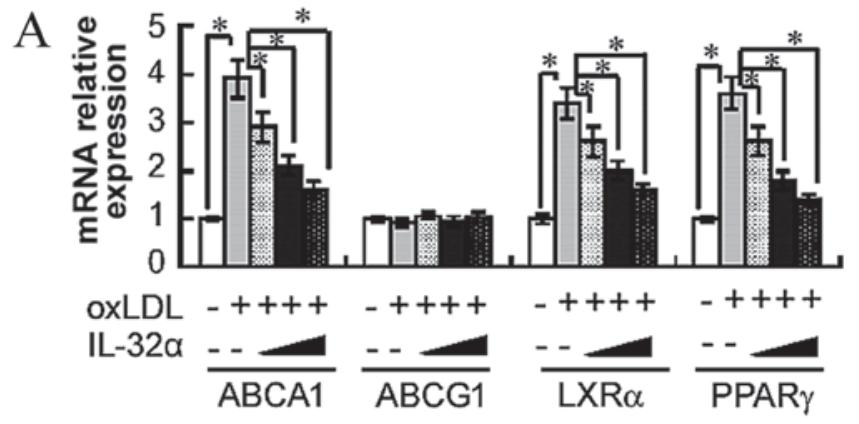

B

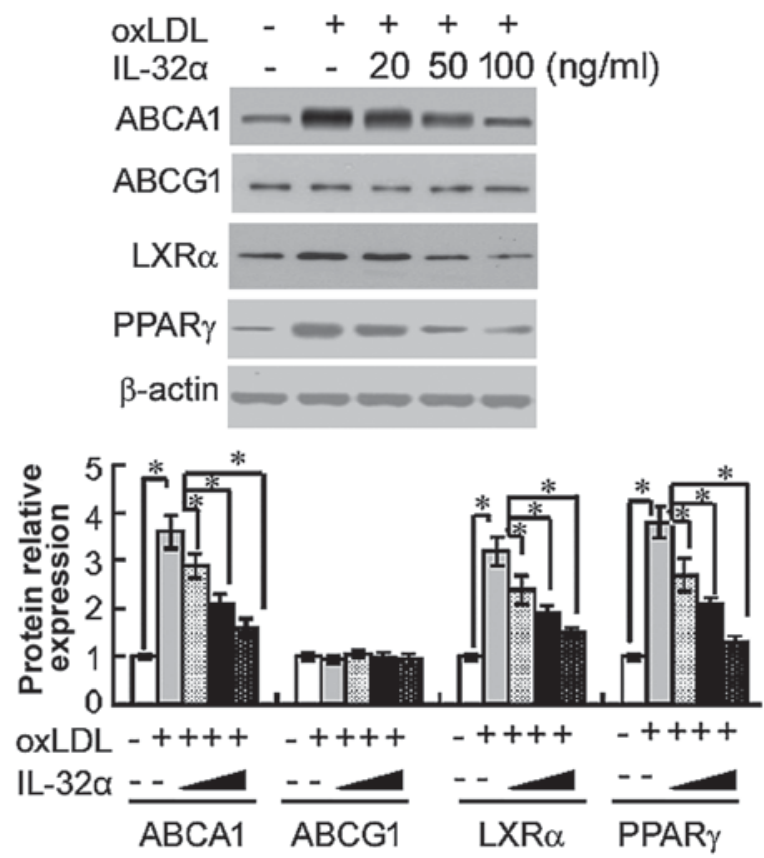

Figure 3. Effects of IL-32 $\alpha$ on the (A) mRNA and (B) protein expression levels of ABCA1, ABCG1, LXR $\alpha$ and PPAR $\gamma$ in ox-LDL-stimulated THP-1 macrophages, as determined by quantitative polymerase chain reaction and western blot analysis, respectively. THP-1 macrophages were pretreated with different concentrations of $(20,50$ and $100 \mathrm{ng} / \mathrm{ml})$ of IL-32 $\alpha$ for $6 \mathrm{~h}$, followed by incubation with ox-LDL for $72 \mathrm{~h}$. Data are expressed as the mean \pm standard deviation $(n=3)$. "P $<0.05$. IL-32 $\alpha$, interleukin-32 $\alpha$; ox-LDL, oxidized low-density lipoprotein; ABC, ATP-binding cassette transporter; LXR $\alpha$, liver X receptor $\alpha$; PPAR $\gamma$, peroxisome proliferator-activated receptor $\gamma$.

(Fig. 4A and C) and increased the expression levels of ABCA1 and LXR $\alpha$ (Fig. 4B and D) in ox-LDL-stimulated THP-1 cells .

\section{Discussion}

In the present study, the effects of treatment with IL-32 $\alpha$, the most abundant transcript of the pro-inflammatory cytokine IL-32, were investigated in ox-LDL-stimulated THP-1 cells. The results revealed that IL-32 $\alpha$ increased lipid deposition and dose-dependently decreased the cholesterol efflux from ox-LDL-stimulated THP-1 macrophages. In addition, IL-32 $\alpha$ attenuated the expression levels of ABCA1, LXR $\alpha$ and PPAR $\gamma$. To determine the mechanism of IL-32 $\alpha$-mediated inhibition of cholesterol efflux, PPAR $\gamma$ overexpression was performed in THP-1 macrophages by transfection. PPAR $\gamma$ overexpression abrogated the IL-32 $\alpha$-mediated inhibition of cholesterol efflux and reversed the IL-32 $\alpha$-mediated downregulation of ABCA1 and LXR $\alpha$. Thus, it was demonstrated that IL-32 $\alpha$ inhibits the 


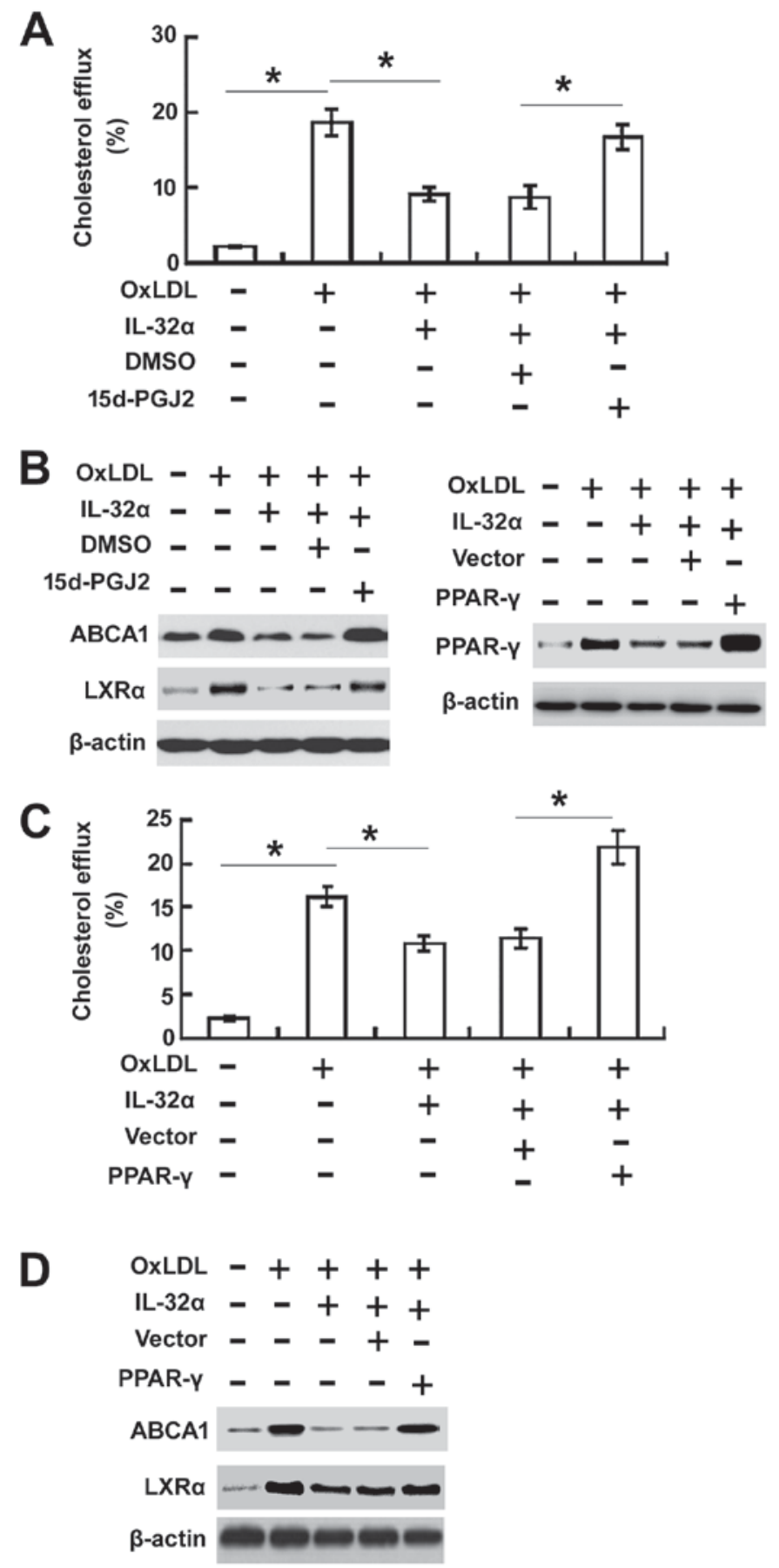

Figure 4. Overexpression of PPAR $\gamma$ rescued IL-32 $\alpha$-mediated inhibition of cholesterol efflux. (A) Cholesterol efflux assay and (B) western blot analysis were performed in THP-1 macrophages treated with the PPAR $\gamma$ agonist $15 \mathrm{~d}-\mathrm{PGJ} 2$ for $1 \mathrm{~h}$, followed by exposure to IL-32 $\alpha$ (50 ng/ml) for a further $6 \mathrm{~h}$. (C) Cholesterol efflux assay and (D) western blot analysis were conducted in THP-1 cells transfected with pcDNA3.1-PPAR- $\gamma$ or pcDNA3.1 vector. Data are expressed as the mean \pm standard deviation $(\mathrm{n}=3)$. ${ }^{*} \mathrm{P}<0.05$. IL-32 $\alpha$, interleukin-32 $\alpha$; ox-LDL, oxidized low-density lipoprotein; ABC, ATP-binding cassette transporter; LXR $\alpha$, liver X receptor $\alpha$; PPAR $\gamma$, peroxisome proliferator-activated receptor $\gamma$.

cholesterol efflux from ox-LDL-exposed THP-1 macrophages by regulating the PPAR $\gamma$-LXR $\alpha$-ABCA1 pathway.

IL-32 was identified as NK cell transcript 4 (NK4), since it was selectively expressed in activated T cells or NK cells (17). The biological role of IL-32 remained unclear until 2005, when Kim et al (13) demonstrated that recombinant NK4 was able to induce several pro-inflammatory cytokines, including TNF- $\alpha$ and IL-8. Therefore, NK4 was renamed to IL-32. The IL-32 gene has six splice variants, including IL-32 $\alpha$, IL-32 $\beta$, IL $32 \gamma$, IL-32 $\delta$, IL-32 $\varepsilon$, and IL-32 $\zeta$ (18), with IL-32 $\alpha$ being the most abundant transcript (14). IL-32 can induce a range of pro-inflammatory mediators and contribute to autoimmune diseases, such as rheumatoid arthritis and inflammatory bowel disease (19). Inflammation serves an important role in the initiation and progression of atherosclerosis and immune disease (20). A range of immune cells, such as macrophages and T-lymphocytes, orchestrate the inflammatory response in atherosclerosis through the action of various cytokines (21). However, the effects of IL-32 $\alpha$ as an inflammatory cytokine in atherosclerosis remain unknown. The present study 
investigated the effects of IL-32 $\alpha$ on lipid deposition and cholesterol efflux. As expected, IL-32 $\alpha$ enhanced lipid deposition and inhibited cholesterol efflux in ox-LDL-stimulated THP-1 macrophages, which simulated a foam cell formation model.

$\mathrm{ABCA} 1$ and $\mathrm{ABCG} 1$ are integral participants in cholesterol efflux and reverse cholesterol transport (21). To investigate the mechanism of the IL-32 $\alpha$-mediated negative effects on cholesterol efflux, western blot analysis was conducted in the present study to explore the protein expression of ABCA1 and ABCG1. The results showed that IL-32 $\alpha$ inhibited the expression of ABCA1, but did not affect the expression of ABCG1, indicating that IL-32 $\alpha$ inhibits cholesterol efflux through the ABCA1 signaling pathway. PPAR $\gamma$ and $L X R \alpha$ are nuclear receptors that serve a pivotal role in macrophage cholesterol homeostasis and inflammation (22). Western blot analysis in the current study demonstrated that IL-32 $\alpha$ attenuated the expression levels of PPAR $\gamma$ and LXR $\alpha$. These results indicate that IL-32 $\alpha$ may inhibit cholesterol efflux through the PPAR $\gamma$-LXR $\alpha$-ABCA1 signaling pathway.

Inflammatory cytokines are involved in all stages of atherosclerosis and have a profound influence on the pathogenesis of atherosclerosis, including cholesterol efflux. IL-6 and TNF- $\alpha$ inhibit cholesterol efflux by suppressing ABCA1 expression (23). IL-1 $\beta$ has been demonstrated to promote lipid accumulation and inhibit cholesterol efflux in human mesangial cells by dysregulating the expression of lipoprotein receptors, thus inhibiting cholesterol efflux through the PPAR-LXR $\alpha$-ABCA1 pathway (24). Furthermore, PPAR $\gamma$ agonists protect mesangial cells from IL-1 $\beta$-induced intracellular lipid accumulation by activating the ABCA1 cholesterol efflux pathway (24). To further investigate the role of PPAR $\gamma$ on IL-32 $\alpha$-meidated inhibition of cholesterol efflux, the present study demonstrated that the PPAR $\gamma$ agonist 15d-PGJ2 and PPAR $\gamma$ overexpression through transfection enhanced cholesterol efflux in ox-LDL-stimulated THP-1 macrophages. These findings indicate that inhibition of PPAR $\gamma$ serves an important role in IL-32 $\alpha$-mediated suppression of cholesterol efflux.

In conclusion, the present study demonstrated that IL-32 $\alpha$ promotes lipid deposition and inhibits cholesterol efflux through the suppression of PPAR $\gamma$-LXR $\alpha$-ABCA1 signaling pathway in ox-LDL-stimulated THP-1 macrophages. However, the role of other isoforms exclusive of IL-32 $\alpha$ in cholesterol efflux remains unknown. Therefore, more studies are required to determine the function of each IL-32 isoform in lipid accumulation and cholesterol efflux.

\section{References}

1. Detmers PA, Hernandez M, Mudgett J, Hassing H, Burton C, Mundt S, Chun S, Fletcher D, Card DJ, Lisnock J, et al: Deficiency in inducible nitric oxide synthase results in reduced atherosclerosis in apolipoprotein E-deficient mice. J Immunol 165: 3430-3435, 2000.

2. Schmitz G, Kaminski WE, Porsch-Ozcürümez M, Klucken J, Orsó E, Bodzioch M, Büchler C and Drobnik W: ATP-binding cassette transporter A1 (ABCA1) in macrophages: A dual function in inflammation and lipid metabolism? Pathobiology 67: 236-240, 1999

3. Bodzioch M, Orsó E, Klucken J, Langmann T, Böttcher A, Diederich W, Drobnik W, Barlage S, Büchler C, Porsch-Ozcürümez $\mathrm{M}$, et al: The gene encoding ATP-binding cassette transporter 1 is mutated in Tangier disease. Nat Genet 22: 347-351, 1999.
4. Glass CK and Witztum JL: Atherosclerosis. The road ahead. Cell 104: 503-516, 2001.

5. Yu XH, Fu YC, Zhang DW, Yin $\mathrm{K}$ and Tang CK: Foam cells in atherosclerosis. Clin Chim Acta 424: 245-252, 2013.

6. Favari E, Zimetti F, Bortnick AE, Adorni MP, Zanotti I, Canavesi $\mathrm{M}$ and Bernini F: Impaired ATP-binding cassette transporter A1-mediated sterol efflux from oxidized LDL-loaded macrophages. FEBS Lett 579: 6537-6542, 2005.

7. Berrougui H, Ikhlef S and Khalil A: Extra virgin olive oil polyphenols promote cholesterol efflux and improve HDL functionality. Evid Based Complement Alternat Med 2015: 208062, 2015.

8. Escolà-Gil JC, Llaverias G, Julve J, Jauhiainen M, Méndez-González J and Blanco-Vaca F: The cholesterol content of Western diets plays a major role in the paradoxical increase in high-density lipoprotein cholesterol and upregulates the macrophage reverse cholesterol transport pathway. Arterioscler Thromb Vasc Biol 31: 2493-2499, 2011.

9. Zhao GJ, Yin K, Fu YC and Tang CK: The interaction of ApoA-I and ABCA1 triggers signal transduction pathways to mediate efflux of cellular lipids. Mol Med 18: 149-158, 2012.

10. Lee JY, Karwatsky J, Ma L and Zha X: ABCA1 increases extracellular ATP to mediate cholesterol efflux to ApoA-I. Am J Physiol Cell Physiol 301: C886-C894, 2011.

11. Ji A, Wroblewski JM, Cai L, de Beer MC, Webb NR and van der Westhuyzen DR: Nascent HDL formation in hepatocytes and role of ABCA1, ABCG1, and SR-BI. J Lipid Res 53: 446-455, 2012.

12. Chawla A, Boisvert WA, Lee CH, Laffitte BA, Barak Y, Joseph SB, Liao D, Nagy L, Edwards PA, Curtiss LK, et al: A PPAR gamma-LXR-ABCA1 pathway in macrophages is involved in cholesterol efflux and atherogenesis. Mol Cell 7: 161-171,2001.

13. Kim SH, Han SY, Azam T, Yoon DY and Dinarello CA: Interleukin-32: A cytokine and inducer of TNFalpha. Immunity 22: 131-142, 2005.

14. Choi JD, Bae SY, Hong JW, Azam T, Dinarello CA, Her E, Choi WS, Kim BK, Lee CK, Yoon DY, et al: Identification of the most active interleukin-32 isoform. Immunology 126: 535-542, 2009.

15. Cheon S, Lee JH, Park S, Bang SI, Lee WJ, Yoon DY, Yoon SS, Kim T, Min H, Cho BJ, et al: Overexpression of IL-32alpha increases natural killer cell-mediated killing through up-regulation of Fas and UL16-binding protein 2 (ULBP2) expression in human chronic myeloid leukemia cells. J Biol Chem 286: 12049-12055, 2011.

16. Livak KJ and Schmittgen TD: Analysis of relative gene expression data using real-time quantitative PCR and the 2(-Delta Delta C(T)) method. Methods 25: 402-408, 2001.

17. Goda C, Kanaji T, Kanaji S, Tanaka G, Arima K, Ohno S and Izuhara K: Involvement of IL-32 in activation-induced cell death in T cells. Int Immunol 18: 233-240, 2006.

18. Kim S: interleukin-32 in inflammatory autoimmune diseases. Immune Netw 14: 123-127, 2014.

19. Conti $P$ and Shaik-Dasthagirisaeb Y: Atherosclerosis: A chronic inflammatory disease mediated by mast cells. Cent Eur J Immunol 40: 380-386, 2015.

20. Buckley ML and Ramji DP: The influence of dysfunctional signaling and lipid homeostasis in mediating the inflammatory responses during atherosclerosis. Biochim Biophys Acta 1852: $1498-1510,2015$.

21. Majdalawieh A and Ro HS: PPARgammal and LXRalpha face a new regulator of macrophage cholesterol homeostasis and inflammatory responsiveness, AEBP1. Nucl Recept Signal 8: e004, 2010.

22. Ramji DP and Davies TS: Cytokines in atherosclerosis: Key players in all stages of disease and promising therapeutic targets. Cytokine Growth Factor Rev 26: 673-685, 2015.

23. Zhang N, Lei J, Lei H, Ruan X, Liu Q, Chen Y and Huang W: MicroRNA-101 overexpression by IL- 6 and TNF- $\alpha$ inhibits cholesterol efflux by suppressing ATP-binding cassette transporter A1 expression. Exp Cell Res 336: 33-42, 2015.

24. Ruan XZ, Moorhead JF, Fernando R, Wheeler DC, Powis SH and Varghese Z: PPAR agonists protect mesangial cells from interleukin 1beta-induced intracellular lipid accumulation by activating the ABCA1 cholesterol efflux pathway. J Am Soc Nephrol 14: 593-600, 2003. 